\title{
OUTCOME OF LAPAROSCOPIC TOTAL EXTRA PERITONEAL VERSUS LICHTENSTEIN REPAIR FOR TREATMENT OF INGUINAL HERNIA: A RANDOMIZED CONTROL TRIAL
}

Ahmed Raza Noumani ${ }^{1}$, Ahmed Siddique Ammar ${ }^{2}$, Muhammad Usman Aslam ${ }^{3}$, Syed Asghar Naqi ${ }^{4}$

\section{ABSTRACT: \\ OBJECTIVES:}

To compare the outcome of laparoscopic total extra peritoneal (TEP) repair versus Lichtenstein repair $(L R)$ of inguinal hernia in terms of post-operative pain, hematoma, seroma, wound infection and early recurrence.

\section{METHODOLOGY:}

This randomized control trial was conducted at Surgical Unit III, General Hospital Lahore, Pakistan during the period June 2017 to May 2018. Male patients aged up to 50 years diagnosed with unilateral, reducible primary inguinal hernia were randomized into two groups, Group $A$ (TEP) and Group B (LR), with 38 patients each. Data was collected prospectively on structured proforma. Patients were regularly followed up for one year for early postoperative complications. Statistical analysis was done using SPSS version 26.

\section{RESULTS:}

Out of 76 patients, mean age for TEP was $36.72 \pm 4.50$ years and LR was $34.42 \pm 6.8$ years. No significant difference was found in both the groups in terms of short-term postoperative complications. $L R$ group had comparatively high rate of postoperative complications; hematoma formation $(n=3 / 38$; $7.9 \%)$, wound infection ( $n=3 / 38 ; 7.9 \%)$ and seroma formation $(n=1 / 38 ; 2.6 \%)$. Postoperative pain with Visual Analogue Score in TEP group on the $1^{\text {st }}$ day, $3^{\text {rd }}$ day, $7^{\text {th }}$ day and 1 month follow up was less as compared to LR group.

\section{CONCLUSION:}

The present study concludes that TEP is better than LR in inguinal hernia in terms of less postoperative pain after 1 month. However, no statistical difference was found in seroma and hematoma formation and wound infection.

KEYWORDS: Inguinal Hernia, Laparoscopic Hernia, Lichtenstein Repair, Hematoma, Pain, Seroma

How to cite this article:

Noumani AR, Ammar AS, Aslam MU, Naqi SA. Outcome of Laparoscopic Total Extra Peritoneal Versus Lichtenstein

Repair For Treatment of Inguinal Hernia: A Randomized Control Trial J Gandhara Med Dent Sci. 2021;8(3): 20-24

DOI: https://doi.org/10.37762/jgmds.8-3.190

\section{Correspondence}

${ }^{2}$ Ahmed Ammar, Senior Registrar, Mayo Hospital,

Lahore

Cell\# +92-333-9981912

email: asammar1912@gmail.com

${ }^{1}$ Senior Registrar, Mayo Hospital, Lahore

${ }^{3}$ Senior Registrar, Mayo Hospital, Lahore

${ }^{4}$ Professor Surgery, Mayo Hospital, Lahore

\section{INTRODUCTION:}

Inguinal hernia by definition is protrusion of a viscus or part of a viscus through inguinal canal. Inguinal hernia is a common surgical condition and a prominent cause of disability and work loss ${ }^{1}$. Globally, the annual incidence of abdominal wall hernia is $100-300 / 100000$, 
$75 \%$ of which occurs in inguinal region with male to female ratio of $7.5: 1^{2}$. Inguinal hernia repair is one of the most common performed procedures with millions of hernias repaired annually worldwide but its treatment continues to evolve ${ }^{3}$. Various surgical techniques like Shouldice repair, Bassini operation, tensionfree hernioplasty (Lichtenstein repair, LR), laparoscopic trans abdominal extra peritoneal hernioplasty (TEP), laparoscopic trans abdominal preperitoneal hernioplasty (TAPP) have been tried but currently no consensus has been reached on the best technique. Ideal treatment is one, which encompasses decreased operation time, rapid time of recovery, low cost, minimal hospital stay, rapid recovery to work and postoperative complications ${ }^{4}$.Lichtenstein inguinal hernia repair is a time tested, safe, effective, well understood procedure with excellent results. Laparoscopic hernia repair (TEP) is relatively newer hernioplasty technique and is debated as a good alternative ${ }^{5}$. It is thought that laparoscopic treatment is better than the open repair in terms of less postoperative pain, quicker return to physical activities, better cosmetic results and low morbidity albeit, most surgeons find it difficult to adopt due to its higher costs, twice longer operative time and its longer learning time ${ }^{6}$. Moreover, a multicentric comparative study on these two techniques revealed no statistically significant difference in terms of postoperative complications $^{7}$. Contrarily, some studies reported lower incidence of postoperative pain in TEP as compared to LR resulting in significant decrease in ambulation time ${ }^{8}$. To date, the preferred approach between TEP and LR remains inconclusive so this study was conducted with the rationale to compare the outcome of TEP and LR of inguinal hernia in our setup.

\section{METHODOLOGY:}

This randomized control trial was conducted at Surgical Unit III, General Hospital Lahore, Pakistan during the period June 2017 to May 2018. Approval from the ethical committee of University of Health Sciences Lahore was taken and non-probability purposive sampling technique was used for sample collection. 76 diagnosed patients of inguinal hernia were selected through consecutive non-probability sampling technique and were randomized using simple balloting, into two groups having 38 patients each for the purpose of treatment, TEP group and LR group. Inclusion criteria comprised of male adults aged up to 50 years diagnosed with unilateral, reducible primary inguinal hernia. Those patients who had sliding hernia, previous lower abdominal surgery, coagulation defects and suffering from any generalized or debilitating disease, diabetes mellitus, unwilling for follow-up, or patients unfit for general anesthesia were excluded. All patients fulfilling the inclusion criteria were admitted one day prior to surgery and examined pre operatively. Routine investigations including complete blood count, liver functions tests, blood sugar random, hepatitis B and C screening, PT, APTT, ECG, $X$-ray chest, and abdominal ultrasonography were performed. Informed written consent was obtained from all the enrolled patients. All patients were given single dose of injection cefuroxime 1-gram intravenous at the time of induction. Patients of both the groups were followed up as out-patients post operatively on $1^{\text {st }}$ day, $3^{\text {rd }}$ day, $7^{\text {th }}$ day, $30^{\text {th }}$ day for postoperative pain, after 30 days for hematoma, seroma and wound infection and up to one year for recurrence. Pain was assessed through Visual Analogue Scale. Statistical analysis of data in this study was performed using statistical package for social sciences (SPSS) version 26. Values were calculated as mean $\pm S D$ for continuous variables and frequency and percentages for categorical variables. Differences in the proportions were calculated using chi-square test. Independent $t$ test was used to test the difference between means of continuous variables. P-value $<0.05$ was considered statistically significant.

\section{RESULTS:}

A total of 76 patients had reported in surgical outpatient department from June 2017 to May 2018 and all of them were managed for inguinal hernia. Overall mean age was $35.36 \pm 5.65$ years with range of $30-48$ years. In TEP group, hernia types were direct type $(n=17 / 38 ; 54 \%)$ and indirect type $(n=21 / 38$;

$46 \%$ ), on the other hand LR group direct hernia and indirect hernia were seen in $(n=14 / 38 ; 46 \%)$ and $(n=24 / 38 ; 54 \%)$ of the cases respectively. Comparison between two groups regarding age showed no significant difference ( $P$-value $>0.05$ ) as shown in Table1) 
Short term post - operative complications revealed no significant difference in both the groups except post-operative pain, which was found to be less in TEP group as compared to LR group (Table 2). Pain assessment using visual analogue score (VAS) at different postoperative days and comparison in both the groups is shown in Table 2 . Significant pain score was found after 30 days of follow-up (P-value $=0.01)$. Postoperative pain was well controlled with oral NASIDS. Overall, four patients $(5.26 \%)$ developed small postoperative hematoma;
(2.6\%) in TEP group and (7.9\%) in LR group, but no intervention was needed and it resolved with conservative treatment. Similarly, seroma developed in only 1 patient $(2.6 \%)$ of LR group, which resolved spontaneously. Wound infection was found in 3 patients $(7.9 \%)$ of LR group which were treated by removal of few stitches, application of local antiseptics dressings and use of oral antibiotics according to culture and sensitivity reports. No hernia recurrence was found in both groups after follow up of one year.

Table 1: Comparison of TEP and LR in Terms of Age of Patients

\begin{tabular}{|l|l|l|}
\hline \multicolumn{1}{|c|}{ Groups } & Mean \pm SD & P-Value \\
\cline { 1 - 2 } $\begin{array}{l}\text { Total Extra Peritoneal } \\
\text { (TEP) }\end{array}$ & $36.72 \pm 4.50$ years & $>0.05$ \\
\cline { 1 - 2 } $\begin{array}{l}\text { Lichtenstein Repair } \\
\text { (LR) }\end{array}$ & $34.42 \pm 6.80$ years & \\
\hline
\end{tabular}

Table 2: Comparison of Post-Operative Complications of TEP and LR Groups

\begin{tabular}{|c|c|c|c|}
\hline Complications & $\operatorname{TEP}(n=38)$ & $\operatorname{LR}(n=38)$ & P-Value \\
\hline Post-Operative Pain (VAS Score Mean) & & & \\
\hline Day 1 & 5.98 & 6.03 & 0.08 \\
\hline Day 3 & 4.82 & 5.09 & 0.11 \\
\hline Day 7 & 3.27 & 4.35 & 0.06 \\
\hline Day 30 & 0.96 & 3.27 & 0.01 \\
\hline $\begin{array}{l}\text { Wound Infection at } 30^{\text {th }} \text { Post-Operative } \\
\text { Day }\end{array}$ & 0 & $3(7.9 \%)$ & 0.24 \\
\hline Seroma at $30^{\text {th }}$ Post-Operative Day & 0 & $1(2.6 \%)$ & 0.09 \\
\hline Hematoma at $30^{\text {th }}$ Post-Operative Day & $1(2.6 \%)$ & $3(7.9 \%)$ & 0.61 \\
\hline Recurrence After 1 Year & 0 & 0 & 0.00 \\
\hline
\end{tabular}

\section{DISCUSSION:}

This randomized control trial was conducted with the aim of comparing the post-operative pain, hematoma and seroma formation, wound infection and recurrence rates in the two method of laparoscopic total extra peritoneal repair (TEP) and Lichtenstein tension free mesh repair (LR) on 76 patients who were selected for this study. No case of recurrence was found in both groups after a follow up of one year. In a study done by Roos et al, recurrence rate of $2.4 \%$ was found after a follow up of 2 years $^{9}$. In our study two commonly used inguinal hernia repair techniques; TEP and LR were compared and no significant difference in postoperative complications including seroma/hematoma formation, wound infection and hernia recurrence was observed (P-value $=0.00)$. However, postoperative pain with VAS in TEP group on first day, third day, the first week and first month follow up was found to be less as compared to LR group (P-value=0.01). A study done by Westin et al showed severe pain in about $2.1 \%$ of patients underwent inguinal hernia repair by total extra peritoneal technique $(P \text {-value }=0.543)^{10}$. In this study, hematoma was found in 1 patient $(2.6 \%)$ after a week in TEP while in Lichtenstein 3 patients 
(7.9\%) after 3rd day (P-value=0.61), which was resolved without treatment. In another study the frequency of hematoma was 10 $(1.5 \%)$ and $10(1.5 \%)$ in TEP \& Lichtenstein groups respectively, with a P-value of $0.893^{11}$. Bringman et al $^{12}$ found hematoma in $3(3.3 \%)$ and $8(7.8 \%)$ of cases in TEP and Lichtenstein respectively. Sazhin and colleagues in a randomized study reported incidence of hematoma to be $16.4 \%$ vs. $13.6 \%$ in TEP and Lichtenstein group respectively which was but relatively higher but insignificant ${ }^{13}$. The incidence of seroma was low in both the groups; $(2.6 \%)$ in LR and none in TEP, which resolved spontaneously. Suciu et al found seroma $0.9 \%$ and $0.8 \%$ cases of TEP and Lichtenstein respectively ${ }^{14}$, while it was reported as $3 \%$ and $9 \%$ in Lichtenstein vs. TEP group. Visual Analogue Pain Score (VAS) was observed by VAS on the $1^{\text {st }}, 3^{\text {rd }}, 7^{\text {th }}$ and $30^{\text {th }}$ day of the follow-up; in TEP group, the mean VAS score on the $1^{\text {st }}$ postoperative day was 5.98 , on the $2^{\text {nd }}$ postoperative day it was $4.82,3.27$ on the $7^{\text {th }}$ postoperative day and 0.96 on $30^{\text {th }}$ postoperative day. While in LR group, the mean VAS score on the $1^{\text {st }}$ postoperative day was 6.03 , on the $2^{\text {nd }}$ postoperative day it was $5.09,4.35$ on the $7^{\text {th }}$ postoperative day and 3.27 on $30^{\text {th }}$ postoperative day. Visual Analogue Score (VAS) scores were found to be lower in TEP group especially on $30^{\text {th }}$ postoperative day as compared to LR group and the differences was statistically significant $(P$-value $=0.01)$. Our findings are in accordance to the prevailing literature ${ }^{15,16}$. The nature of chronic pain was of boring type or pricking sensation or hyperesthesia, which may be due, mesh pricking or nerve cutting injury or nerve damage due to electro cauterization. Infection rate in our study was $3(7.9 \%)$, which was only observed in Lichtenstein group. As reported in another study ${ }^{17}(1.1 \%)$ and $(3.9 \%)$ in TEP and Lichtenstein, and $(1.4 \%)$ in TEP and $(0.7 \%)$ LR reported by Khazaei et $\mathrm{al}^{18}$. All patients of wound infection in our study were managed conservatively and no patient required removal of polypropylene mesh.

\section{LIMITATIONS:}

There are certain limitations to this study. This series of 76 patients is small to permit final conclusions due to study limitations like limited inclusion criteria and short follow up of one month except recurrence rate which was followed up to one year. More studies with large series, flexible inclusion criteria and longer follow-up periods are recommended. Nevertheless, TEP offers the advantage of less postoperative pain and relatively less post-op complications including seroma, hematoma formation and wound infection.

\section{CONCLUSION:}

Laparoscopic total extra peritoneal repair (TEP) has few post-operative complications like post-operative pain, hematoma and seroma formation and wound infection after one month than Lichtenstein repair (LR) by mesh hernioplasty, while no difference is found between two groups regarding recurrence of hernia after one year.

\section{CONFLICT OF INTEREST: None}

FUND SOURCES: None

\section{REFERENCES:}

1. Abboud W, Kamal O, Garcia V, Kluger $Y$, AbuSalih A. The use of self fixating mesh in open inguinal hernia repair. Madridge J Surg. 2018;1(2):47-51.

2. Aliyazicioglu T, Yalti T, Kabaoglu B. Laparoscopic total extraperitoneal (TEP) inguinal hernia repair using 3dimensional mesh without mesh fixation. Surg Laparoscopy Endoscopy Percutaneous Tech. 2017;27(4):282-4.

3. Feleshtinsky YY, Kohanevich AV. Estimation of options of the mesh implant fixation in transabdominal preperitoneal alloplasty in patients with inguinal hernia. Med Perspect. 2019;24(1):46-9.

4. Gasser J. Information rights in Liechtenstein foundations, reloaded: back to the future?. Trusts Trustees. 2016;22(7):767-74.

5. Gupta S, Goyal S, Sharma R, Attri AK. Lichtenstein repair using lightweight mesh versus laparoscopic total extraperitoneal repair using polypropylene mesh in patients with inguinal hernia: a randomized study. Saudi Surg J. 2019;7(4):148-53. 
6. Khalil AA, Ebeid EF, Ismail Al. Comparative study between the use of self-fixating mesh and non-selffixating mesh in laparoscopic inguinal hernia repair transabdominal preperitoneal technique. Egypt $\mathrm{J}$ Surg. 2019;38(3):588-96.

7. Trejo-Avila $\mathrm{M}$, Bozada-Gutiérrez K, Valenzuela-Salazar C, HerreraEsquivel J, Moreno-Portillo M. Sarcopenia predicts worse postoperative outcomes and decreased survival rates in patients with colorectal cancer: a systematic review and meta-analysis. Int Colorectal Dis $2021: 1$-20.

8. Kryvoruchko IA, Sivozhelezov AV, Sykal NA, Chugay VV, Tonkoglas AA. Laparoscopic plastic of inguinal hernias. J Educ Health Sport. 2019;9(2):538-45.

9. Roos M, Bakker WJ, Schouten N, Voorbrood C, Clevers GJ, Verleisdonk EJ, et al. Higher recurrence rate after endoscopic totally extraperitoneal (TEP) inguinal hernia repair with ultrapro lightweight mesh: 5-year results of a randomized controlled trial (TULP-trial). Ann Surg. 2018;268(2):241-6.

10. Westin L, Wollert S, Ljungdahl $M$, Sandblom G, Gunnarsson $U$, Dahlstrand $U$. Less pain 1 year after total extra-peritoneal repair compared with Lichtenstein using local anesthesia. Ann Surg. 2016;263(2):240-3.

11. Usman M, Saleem K, Dab OR, Khan RA, Hayat $S$, Lateef AU. Comparison of open mesh Hernioplasty with Laparoscopic total extraperitoneal (tep) mesh repairs for inguinal hernias.

The Prof Med J 2019;26(07):1090-5.
12. Patel DA, Vaghasiya GN, Patel JR. Prospective comparative study of laparoscopic totally extraperitoneal versus Lichtenstein's tension free open meshplasty for management of inguinal hernia. International Surgery J. 2020;7(3):647 -54.

13. Sazhin AV, Andriyashkin AV, Ivakhov GB, Mamadumarov VA, Nikishkov AS, Loban KM, et al. Analysis of surgery for inguinal hernia under hernia center. Med J Russ Fed. 2018;24(4):176-9.

14. Suciu BA, Halmaciu I, Fodor D, Trambitas C, Godja D, Clipa A, et al. Comparative study on the need for postoperative analgesic medication after surgical treatment of inguinal hernia with surgical mesh through laparoscopic or classic approach. Mater Plast. 2018;55(3):380-4.

15. Urkan $\mathrm{M}$, Peker YS. TEP versus Lichtenstein, which one to choose? :a retrospective cohort study. Rev Assoc Med Bras. 2019;65(9):1201-7.

16. Sawarkar P, Zade R, Dhamanaskar S, Gathe B, Sawardekar P, Khade A. Feasibility of laparoscopic inguinal hernia repair (TEP) in rural centre in India. I Surg J. 2017;4(7):2336 -41.

17. Patel DA, Vaghasiya GN, Patel JR. Prospective comparative study of laparoscopic totally extraperitoneal versus Lichtenstein's tension free open meshplasty for management of inguinal hernia. International Surgery Journal. 2020 Feb 26;7(3):647-54.

18. Khazaei AR, Jahromi AR, Khoshfetrat $M$, Alizadeh $R$, Behnampoor $M$. Comparison of bassini and shouldice surgery methods in the inguinal hernia surgery in terms of relapse and pain rate. Pak J Med Health Sci. 2019;13(1):206-9.

\section{CONTRIBUTORS}

1. Ahmed Raza Noumani - Concept \& Design; Data Acquisition; Data Analysis/Interpretation; Drafting Manuscript; Critical Revision; Supervision; Final Approval

2. Ahmed Siddique Ammar - Concept \& Design; Data Acquisition; Data Analysis/Interpretation; Drafting Manuscript; Critical Revision; Supervision

3. Muhammad Usman Aslam - Concept \& Design; Data Acquisition; Data Analysis/Interpretation; Drafting Manuscript; Critical Revision; Supervision

4. Syed Asghar Naqi - Concept \& Design; Data Acquisition; Data Analysis/Interpretation; Drafting Manuscript; Critical Revision; Supervision 